which is also the location of EISCAT's administrative headquarters.

Under the terms of the original agreement signed by six member governments, 25 per cent of the operating costs are currently carried by its three largest member states - Britain, France and Germany - and the remaining costs are split between Norway, Sweden and Finland in a ratio 10:10:5.

The presence of the EISCAT transmitter has certainly helped to put Norway on the scientific map at a relatively low cost. "If you look at the economic side alone, it is a fantastic scoop for Norwegian science," says Asgeir Brekke, professor of physics at the University of Troms $\varnothing$, who was last month elected chairman of the EISCAT council for the next two years.

"We pay only 10 per cent of the running costs, and the rest is paid for by the other participating countries. The result is that we are bringing in more money to the Norwegian community than we are spending. That is very unusual to say that you are doing basic research without being a load on the taxpayer."

EISCAT itself has already proved to be a highly successful facility, producing a string of useful scientific results on the physics of the upper atmosphere. Svalbard's position means that the new radar, which will be operated in co-ordination with the existing facilities, will offer space physicists a unique opportunity to observe those regions of the ionosphere and magnetosphere that are currently inaccessible to ground observation, including the region immediately above the North Pole.

In particular, the new radar will allow the simultaneous observation of the interaction of solar-wind particles with the ionosphere by optical and radar means, since during the winter months it is still dark during the day when particles from the Sun have relatively direct access to the atmosphere.

Norway's enthusiasm to see the new radar built has led it to agree to contribute SKr37 million towards the construction costs, a considerably higher percentage than its current contribution to EISCAT. This is partly explained by the fact that the Norwegian government's enthusiasm for the new radar is not motivated just by the science.

The construction work on the radar and subsequently providing the infrastructure and services needed to maintain it -- will provide much-needed jobs for a region now experiencing high unemployment as a result of a decline in the local mining industry, previously the principal source of work. And continued political instability in Russia means that Norway is keen to maintain a presence in the region.

NATURE - VOL 360 - 10 DECEMBER 1992

\title{
Alternative view on whaling
}

WHEN Mrs Gro Harlem Brundtland, the Norwegian Prime Minister, chaired the international commission that endorsed the term "sustainable development" in the mid-1980s, she became a heroine of the world's environmentalists. This summer, however, her halo became severely tarnished when Norway announced that it planned to defy the current international moratorium on commercial whaling.

To many outside Norway, there seems a clear conflict between a desire to respect nature and a desire to exploit it. But inside Norway, the positions are seen as entirely compatible. "Any resource which can be harvested on a sustainable basis - and as a scientist I believe that this applies to whales - should be harvested," says Arnoldus Schytte Blix, director of the department of arctic biology at the University of Troms $\varnothing$. "Not doing that is a waste of resources."

Inevitably, the country's scientific community has become embroiled in the controversy over Norway's stance on commercial whaling. One reason is the government's desire to demonstrate that its position is supported by scientific evidence that whale populations are not in a particularly precarious state (just as it has used comparable arguments elsewhere to justify restrictions on exploiting various species of fish).

"The most important part of our research on whales has been the nonlethal part, in particular the development of new methods for counting whale populations," says Lars Walløe, professor of physiology at the University of Oslo, chairman of the country's Natural Environment Research Council, and a close adviser to Mrs Brundtland.

In particular, Walløe points out that the scientific committee of the International Whaling Commission has now accepted Norway's assessment that the world's population of minke whales is about 80,000 - not 18,000 , as had previously been estimated.

There is still dispute over the algorithm being used to calculate the precise number of minke whales that can be caught without posing a serious threat to the remaining population. More controversial, however, is the fact that Norway has also announced that it intends to use 400 of the whales caught over the next three years to study their feeding habits.

Walløe defends this research as necessary for the future not just of the whaling industry but of Norway's fishing industry more broadly. "We know that minke whales eat a large amount of food; they may eat crustaceans, they may even eat cod," he says. "Finding out the eating habits of whales is not perhaps a major scientific goal in itself; but from the fishing industry's point of view it is fairly important."

Blix points out that analysis of 50 whales studied over the past five years during which "scientific whaling" has been permitted under the terms of the international moratorium has already produced detailed results on how much energy an individual whale needs at different times of the day and year.

"The big missing link is their diet: what do they choose to eat, and in which part of the Atlantic?" says Blix. "You need to know more than just the number of individuals involved; you need to know where they are and what they prey on at different times of the ycar."

Blix is quick to respond to charges that he is now seeking an excessively large number of whales for the second part of

\section{Norwegian Prime \\ Minister \\ Brundtland, both \\ heroine and \\ villain in \\ 'green' circles.}

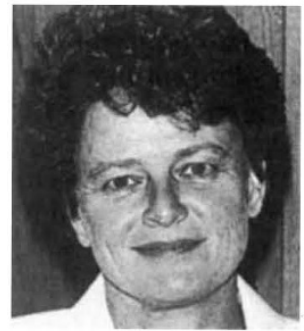

the study. "To arrive at data on food consumption, on a species-wide basis, we need to look at animals in five different areas of the North Atlantic and the Barents Sea at three different times of the year; taking, for example, six whales in each sample already gives us a total of about 100 whales a year."

Some scientists feel that the government's decision to allocate the relatively generous sum of NKr120 million ( $£ 20$ million) over a five year period to whale research represents an unacceptable political bias. They argue that the government appears more concerned with legitimizing its position in international negotiations and in responding to the demands of Norway's powerful whaling lobby than in meeting genuine scientific curiosity.

"Political motivation is stretching too far into the science," says Dat von Graven, a biologist at the University of Trondheim. Others are beginning to express the views of animals rights groups in other countries that whales should be given special protection from whalers and research scientists alike.

Blix, however, is unfazed by criticism. "Hunting, trapping and fishing have been part of everyday life up bere; until recently, they have been activities on which your life depended. In the near future, Norway will be the only Western country in which you can maintain a rational link with nature." 